\section{Synaptic Transmission in Neurosecretory Cells}

SINCE Scharrer's discovery ${ }^{1}$, many types of neurosecretory systems have been investigated histologically in almost all kinds of animals. However, there is no publication dealing with them in terms of electrical activities except the brief note of Potter and Loewenstein ${ }^{2}$, in which the presence of synapses between neurosecretory cells and other nerve cells was only indirectly indicated.

The caudal neurosecretory system of the eel, Anguilla japonica, was found by Enami ${ }^{3}$. In this system the cells are fairly large and clearly seen in fresh material under a dissecting microscope. This fact enabled us to use the micro-electrode technique, and the results obtained with this method clearly showed the synaptic transmission at the cell-bodies as well as other characteristics of the nervous function.

After the caudal spinal column of approximately 20 vertebræ was isolated from the eel, the spinal cord was exposed at several vertebræ including the tail end. This preparation was fixed with 'Vaseline' on a paraffin block in a leucite chamber, and the exposed spinal cord was washed sufficiently with the teleost Ringer. Intracellular records from the cell-bodies of these neurosecretory cells showed resting membrane potentials of $50-60 \mathrm{mV}$. inside negative and overshoots of $10 \mathrm{mV}$. or more in action potentials. The

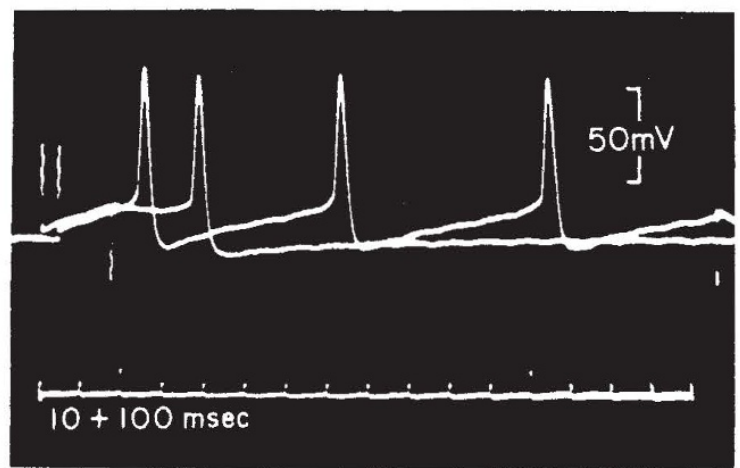

Fig. 1. Spike potentials of a cell body elicited by outward current puises. The responses to brief and long pulses are superimposed
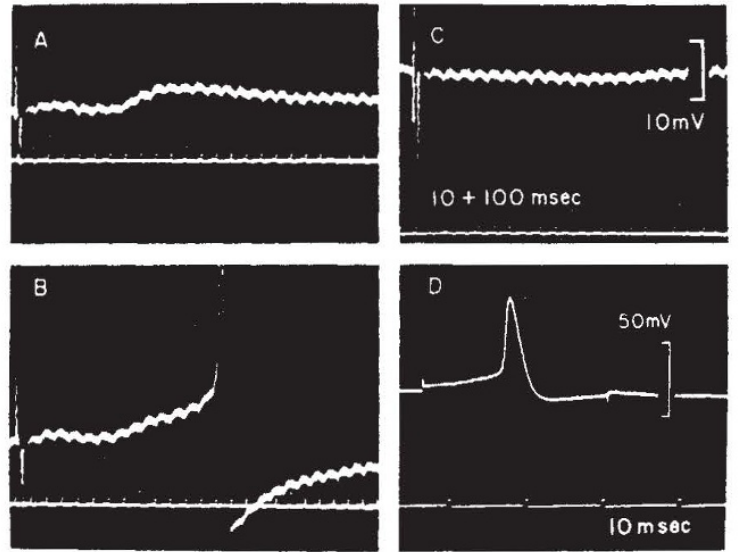

Fig. 2. An experiment showing synaptic transmission. $A$, synaptic potential evoked by a rather weak stimulation of a spinal cord at an anterior part; $B$, synaptic potential followed by a spike in the case of a stronger stimulation; $C$, after treatment of the spinal cord with potassium chloride in a region between the thulath and recording positions. The stimulus was much stronger than in $B ; D$, after $C$, the cell was directly stimulated duration of the action potential was 8-10 msec. at $14-17^{\circ} \mathrm{C}$. and the threshold membrane depolarization was around 12-13 mV. A long lasting outward current pulse resulted in repetitive discharge of spikes, at the end of which an under-shoot of the membrane potential was clearly seen (Fig. 1). These characteristics are very similar to those of the spinal ganglion cells of the frog ${ }^{4}$.

When the spinal cord was stimulated at an anterior segment, a slow potential change was recorded from the neurosecretory cell-body after some delay (Fig. $2 A$ ). If the stimulus was strong enough, a spike potential was initiated at the summit of the slow potential (Fig. 2B). After this spinal cord was treated with potassium chloride in a region between the stimulating and recording positions, no electrical changes were evoked by a stimulus several times as strong as that which could elicit the spike potential (Fig $2 C$ ). Even then, this cell responded to a stimulus directly applied to the cell-body (Fig. 2D). Thus, the slow potential mentioned above may be safely regarded as the synaptic potential, which is also supported by the fact that the temporal summation was clearly observed. The conduction velocity of the fastest fibres in the presynoptic nerve was about $0.6 \mathrm{~m}$./sec. at $15^{\circ} \mathrm{C}$., but that of the neuro-secretory cell could not be measured owing to the short length of the axone, though antidromic stimulation of it was possible.

From the results of the present work it may be concluded that the neurosecretory cells have complete nervous characteristics, and that the activities of these cells are controlled by axones from higher nervous centres, though their locations are quite open for further investigations.

HIROMTCHI MORITA TAKAAKI ISHIBASHI SATORU Yamashita

Department of Biology,

Faculty of Science,

Kyushu University, Fukuoka.

${ }^{1}$ Scharrer, E., Z. vergl. Physiol., 7, 1 (1928).

Potter, D. D., and Loewenstein, W. R., Amer. J. Physiol., 183, 652 (1955).

${ }^{3}$ Enami, M., Gunma $J$, Med. Sci., 4, 23 (1955).

' Ito, M., Jap. J. Physiol., 7, 297 (1957).

\section{Changes in Blood Serotonin during Exposure to Cold}

SERotonin is a recently discovered biogenic amine which can be extracted from brain, blood, and other organs, and which is active on a wide variety of systems when injected into the animal ${ }^{1}$. Gathering of knowledge concerning serotonin's physiological importance has been slowed by an inability to observe fluctuations in its concentration in brain and other tissues, in a wide variety of circumstances simulating physiological mobilization ${ }^{2-4}$. A single exception to this is the observation of a release of serotonin into the bowel, controlled by, and in turn modifying, peristaltic activitys. Also, more recently, Toh has reported rat brain serotonin to drop following exposure to cold associated with drop in body-temperature of $36-30^{\circ} \mathrm{C}$. (ref. 3).

Below I present further data relating serotonin to natural mechanisms, reporting serotonin perturbations in the rat's blood during a short-term exposure to cold, not associated with change in body tem- 